Gender Liminality: The Effects of Gender Inequalities on Female Subjectivity in Hookups and Relationships

\begin{abstract}
College hookup culture research suggests that there is a new double standard of sexual injunctions that heterosexual cisgender females must follow in order to avoid being stigmatized when pursuing sex outside of relationships. While relationships provide women with greater sexual satisfaction, some women prefer hookups because inequalities still exist within relationships. The following paper examines the effects of college hookup culture on female subjectivity and suggests that gender inequalities reposition women into a state of gender liminality. This liminal space is a middle ground between the stereotypical statuses of passive "feminine-object" and agentive "masculine-subject" that prompts women to negotiate how they perform femininity without losing agency.
\end{abstract}

\title{
Introduction
}

Although the sexual and gender revolutions engendered progress that allowed women to benefit from greater sexual parity, college hookup culture research indicates a new sexual double standard that latently reinforces gender inequalities in hookup spaces (Armstrong, England, and Fogarty, 2010). In spite of these disparities and their reinforcement of the gender binary, women report preference for hookups because of reasons that reveal gender inequalities in relationships. The following argues how gender inequalities create an interstitial space referred to as gender liminality, a middle ground between stereotypical gender performances of masculinity and femininity. Gender liminality suggests a complex picture in which heterosexual women find 


\section{Vivid 2}

themselves enacting their agency in relational spaces that have been historically predominated by a binary that privileges men and reproduces double standards.

This analysis first aims to contextualize college hookup culture in order to foreground the orgasm gap findings and consequences of how the sexual double standard manifests and regenerates gender inequalities. That both sexes appear to acknowledge and accept double standards begs the question, why are women accepting unequal access to sexual pleasure in hookups? Reasons as to why women may be reticent to challenge double standards are overviewed, as is the notion of the internalization of norms around gender performance, and how these internalizations support the breaking of the binary through gender liminality. The reasons behind female students' preference for hookups over relationships are examined in order to demonstrate inequalities in relationships, namely how relationships make women more vulnerable to rejection, conflict with their self-development objectives, and can involve abusive and controlling behaviors from male partners. It is suggested that the rejection-avoidance reason is a contradictory stopgap that trades one negative emotional state, that of rejection, for another, unworthiness. Each of these accounts support how gender inequities still occupy the space of relationships and leave women bereft of equal rights in both casual hookups and committed relationships, which further suggests women's liminal status between masculine-subject and feminine-object. Lastly, potential directions for future research are explored, including the study of relational spaces of non-binary LGBTQ individuals so to examine what subjectivity and equality look like outside of normative gender constructs. How might difference exist without the binary? 


\section{Vivid 3}

\section{Contextualizing Hookup Culture and the Orgasm Gap}

Armstrong, England, and Fogarty (2010) examine the sexual experiences of college students through extensive analysis of data from qualitative interviews and an online survey of nearly thirteen thousand students. Contextualizing the term, "hookup," elucidates the sexual practice that many heterosexual young adults are engaging in as both an alternative and formative stepping-stone to relationships. The hookup refers to sexual relations outside of exclusive relationships, which could involve kissing or touch, hand to genital stimulation, oral sex, vaginal intercourse, etc. (England, 2013). While hookups have not supplanted relationships, they have cemented themselves in the formative process of building relationships (Armstrong, England, et al., 2010), suggesting that hookups can lead to dates and subsequent dating. While most hookups do not lead to relationships, England asserts how many relationships commence with a hookup, just as many relationships commenced with the date fifty years ago (2013). Differentiating between the two relational concepts of "the hookup" and "the date" contextualizes their modern inversion, with the "date" often repositioned after hookups as an indicator of relationship potential (England et al., 2008).

What is compelling about heteronormative college hookup culture beyond its primacy as a popular coupling practice and storied relational engagement is the prevalent orgasm gap, a research finding that indicates how males have a significantly higher number of orgasms than females in all relational spaces, yet, most substantially in first hookups. Sexual pleasure was measured through the orgasm, which indicates inequities in the fulfillment of male and female sexual satisfaction, along with gender gaps in initiation, number of partners, and types of sexual behaviors performed (Armstrong, England, et al., 2010). While one might posit that hookup spaces attempt to equalize pleasure affect and practices outside of committed relationships and 


\section{Vivid 4}

give young people more situational spaces to explore themselves and each other, orgasm gap findings suggest that hookup spaces latently reproduce gender inequalities.

Why are men orgasming more than women in hookups? One provision that underlies why the female orgasm appears to be largely unattended in hookup spaces suggests that women's pleasure equity is contingent upon achieving the status of a repeat hookup or relationship. Armstrong mentions how there may be a lack of incentive from male partners to satisfy their female hookup partner sexually, with a greater incentive occurring when a repeat of the sexual encounter is likely. The likelihood of repeat sexual encounters are highest in relationships and when people hook up three or more times, which can be referred to as repeat hookups (Armstrong, England, et al., 2010). Repeat hookups extend to thirty-three percent of the studied sample and are sometimes referred to as "friends with benefits," often featuring amiable socializing before and after the hookup (Armstrong, Hamilton, and England, 2010). While men's orgasm rate appears unchanged across familiarity differentials, there is a marked orgasm-increase for women when they hook up with a familiar face (England, 2013). The idea that women are more comfortable hooking up with someone they know better is supported by how England found that roughly just thirteen percent of students report complete unfamiliarity with the person they hook-up with (2013). Although great strides have been made in the normative current around women's engagement in premarital sex, with premarital sex now acceptable, and acceptable "for women to enjoy it" (Armstrong, England, et al., 2010), orgasm gap findings suggest that women's sexual pleasure is denied or constrained in spaces outside of repeat hookups and relationships. Taking a deeper look at the dimensions of how double standards manifest may help explain these findings. 


\section{Vivid 5}

\section{Dimensions of the Sexual Double Standard}

While in relationships, women orgasm seventy-nine percent as often as men, yet, when women hook up with a man for the first time, they orgasm just thirty-two percent as often as men (Armstrong, England, et al., 2010). What might help explain this sexual pleasure imbalance? What the findings of Armstrong et al. suggest is that "a new version of the old sexual double standard" undergirds the gender gap in orgasm (2010, p. 362). While the hookup space purports itself as a fun alternative where both sexes can receive sexual pleasure outside of relationships, it is suggested that women are judged more harshly than men for pursuing sexual pleasure outside of relationships (Armstrong, England, et al, 2010). Many cultures advocate for gender equality in words, but not in action, as evidenced by the new sexual double standard that maintain different criteria for men's and women's sexual behaviors outside of relationships. In fact, one could posit that the sexual double standard and orgasm gap mutually reinforce each other, as purported beliefs about double standards reproduce the orgasm gap, which then reinstates the double standards that created it in the first place. The consequences of this recursive reinforcement will be explored by examining some significant dimensions of the sexual double standard that hold both men and women accountable for its subsistence.

One dimension of the new sexual double standard examines who is more entitled to receive oral sex, as both sexes appear to devalue women's right to orgasm. Oral sex is a type of sexual behavior that often leads to orgasm, as findings reflect that nearly three-quarters of women find oral sex a positive catalytic experience for their orgasm (Backstrom, Armstrong, and Puentes, 2012). Despite these findings, Armstrong et al. demonstrated how both sexes fit a gendered script that generously entitles males to fellatio on the first hookup, with men receiving higher rates of oral sex than women across all contexts (2010). While both sexes are reportedly 
more likely to orgasm in repeat hookups and even more likely in relationships, men receive oral sex around eighty percent throughout all relational contexts, which differs from women, who receive it forty-six percent of the time in first hookups and sixty-eight percent of the time in relationships (Armstrong, England, et al., 2010). Another statistic that helps explain the orgasm gap is seen through rates of autoeroticism, with women engaging in masturbation just four percent of the time in first hookups in comparison to twenty-four percent of the time while in relationships. It appears as if both masturbation and oral sex help women orgasm, yet few women are allowing themselves to assert their desire to masturbate and request oral sex (Armstrong, England, et al., 2010). Perhaps women would be more apt to actualize selfstimulation and requests for oral sex if men expressed greater concern and care for first-hookup partners, yet, as of now, it seems as though women accept their sexual pleasures as contingent upon men's commitment to them. In fact, one may find it surprising that Armstrong, England, et al. found that both sexes express ambivalence about women's right to orgasm and offer greater support for women's entitlement to sexual pleasure within committed relationship-spaces over hookup-spaces (2010). Despite decades of progress that allow women to experience premarital sex, self-directed sexual pleasure, and reciprocal oral sex without condemnation, each of these events are still largely dependent on a woman's location within a committed relationship (Armstrong, England, et al., 2010).

Another dimension of how both sexes uphold double standards manifests in who is more entitled to receive care and concern, as both sexes appear to expect women to present greater care and concern in the hookup space. While men report expressing greater care and concern for relationship partners over hookup partners, women consider the sexual pleasure of their hookup partners and relationships partners equally (Armstrong, Hamilton, et al., 2010). In addition, when 


\section{Vivid 7}

a male does express care for his female hookup partner's pleasure, it may only be an indirect way of satisfying his own sexual prowess and masculine ego (Armstrong, England, et al., 2010), which may indeed magnify if the male believes that they are giving their female partner an orgasm when they actually are not, as evidenced by females feigning orgasm. Faking an orgasm is a norm that exemplifies the effort and care females give in order to satisfy their male partner, as one female student reports, “to make that person feel good, to make them feel like they've done their job" (England et al., 2008, p. 538). While some women seem to be okay with faking orgasms to elevate the ego of their male hookup partner, others are left feeling demeaned. Personal accounts from female interviewees conducted from 2006-2008 narrativize how degraded some women feel after one-sided hookups in comparison to when sexual satisfaction is mutually considered (Armstrong, England, et al., 2010). The double standards of who is entitled to oral sex and who is expected to unselfishly deliver unreciprocated care and concern elucidate how hookup spaces perpetuate gender inequalities by implicitly denying women of sexual pleasure and emotional care while explicitly privileging men.

One final dimension of how the double standard manifests in hookups lies within "slutshaming" behaviors that force women to negotiate partner-number and how far they go during hookups. One female student mentions how males are entitled to sexually exploring as many women as possible to "make them more of a man", yet, if a woman were to do the same, she would be labeled a "ho" and "not as quality of a person" (Armstrong, Hamilton, et al., 2010). While women are slut-shamed, it appears as though males are encouraged by their peers to fulfill a standard that promotes the fraternal objectification of women while posing low-to-no risk to the male, which essentially translates to pursue and achieve as much sexual activity as possible. When asked about the idea of forming a relationship with a hookup partner, one male 
interviewee responded with, "There's no way I can date her, but she's hot for a hookup" (England, 2008, p. 539). It is suggested that each of the aforementioned double standards and their accompanying injunctions of what a woman should or should not do in the hookup space force women to tread carefully in how they navigate their sexual behaviors to ensure that they safely live up to normative expectations of the hookup space so to retain their access to it.

\section{Beliefs and Internalizations: Why Some Women Accept Double Standards}

Some women are rather aware and seem accepting of double standards. It is important to consider why women seem to accept sexual double standards if it perpetuates the gender binary that privileges men and disadvantages women. Allison and Risman posit that some women's acceptance of gender inequalities is their way of distinguishing themselves from other women in order to "elevate their reputation and status among peers" (2013, p. 1192). One might consider this a mirroring technique, in that male peers may recognize themselves within these women's beliefs, aggrandize the women as superior, and then pursue them more because of this selfidentification. This could also be what is occurring when women are "slut-shamed" by female peers for hooking up with too many people or going too far too soon (Armstrong, England, et al., 2010. Women who slut-shame could be attempting to elevate their status by aligning with male peers to collectively ridicule female peers who pursue sexual pleasure outside of the sanctioned chambers of committed relationships in the wrong way or too soon.

Alternatively, women may not feel confident about asserting their agency more because they lack confidence and pride in the physical appearance and condition of their bodies. Many women grow up learning cultural norms that promote strict ideals of what one's body should look like in order to appear attractive to others. Positive public opinions of female genitalia and 


\section{Vivid 9}

diverse "imperfect" bodies are wanting in the arena of popular media outlets, as the media perpetually instills a degree of self-shame concerning the appearance of female bodies and genital perception (Backstrom et al., 2012). If women do not value their bodies, nor have a positive perception of their genitals, it might be easier to conform to cultural standards of acceptable feminine body types in order to avoid derision than assert their desire for equal sexual pleasure.

In addition, women who are invested in accomplishing gender by expressing their feminine "nature" (West and Zimmerman, 1987) may fear that demanding equal sexual rights in hookup spaces might be read as accomplishing too much masculinity. While expressing agentive power and subjectivity in the hookup space could risk rejection from male hookup partners, it could also help bridge the gap in gender differences that the binary creates. If belief affects behavior, seeing gender differences and believing that these differences are grounds for inequalities may cause one to behave in a way that reflects those beliefs. Judith Lorber speaks to gender and its production of inequality as a surviving institution, highlighting the notion that seeing difference justifies inequality (Risman, 2004). The hookup space and its stark strata of female and male sexual pleasure differentials allow women to see difference and legitimize inequalities, which then further reproduces inequalities. Erving Goffman (1977) speaks to the reproduction of inequalities by way of effects of beliefs on behavior, asserting that beliefs about gender differences are in proximal interaction with actual objective behavior, and that assimilation with normative worldviews could result in self-fulfilling gender behavior. It may be that women have unconsciously internalized the belief that they are naturally the lesser sex, with needs deservedly left unmet, which may influence why some women appear to accept the sexual 
double standard and perform stereotypically passive feminine actions in a male-driven hookup space.

Looking more deeply into how internalizations reproduce inequalities brings social processes back to the personal vis-à-vis England. England examines the indirect effects of constraints on individuals' outcomes in her 2015 study of how constraints affect personal characteristics, which, in turn, affect outcomes. England emphasizes the weight of the personal in this context by referencing Bourdieu's theory of habitus à la Loïc Wacquant, "the way society becomes deposited in persons in the form of lasting dispositions, or trained capacities and structured propensities to think, feel and act in determinant ways, which then guide them" (2015, p. 8). The recursive relationship between the self and the social, and how one's habitus is architected and guided by society, includes gender norms purveyed at an early age around how one must correctly perform masculinity or femininity. As the less resourced sex, it would be worth further examining how women communicate beliefs about their self-worth, and consequently, how they orient themselves in the hookup spectra that run contrary to chauvinistic feelings maintained around gender equality. Do women find the hookup space to be empowering or disempowering for female bodies, and how might they speak to their role in perpetuating or combating norms around gender performance? Investigating how women speak to their own habitus may bring greater awareness to internalized gender norms and expectations that could affect the systems and dynamics that maintain gender inequalities.

\section{Breaking the Binary: Inquiry into Gender Liminality}

Moving the personal back to the social, why is it that some women acknowledge and accept double standards? Is the binary so deeply embedded and internalized that there are no 
other options other than to accept the hand society has dealt, and just deal with it? Journalist Laura Sessions Stepp's assertion that “girls can't be guys in matters of the heart, even though they think they can" (Armstrong, Hamilton, et al., 2010, p. 23) assumes that masculine-agency and casual sex are strictly endeavors of the male gender. Stepp's statement is reductionistic because it presupposes something essential in men that women can never possess. In contrast, England's 2016 review of Lisa Wade's book, American Hookup: The New Culture of Sex on Campus, synthesizes the asymmetry of gender change and how society is more willing to accept women's adoption of characteristically-male qualities than men's adoption of characteristicallyfeminine qualities. This oppositional binary necessitates a dialectic that must be engaged together for any real change to take place on either end, as masculine norms for men are as much of an issue as feminine norms are for women. Yet, that society is more apt to accept female masculinity is evidence of why women have been able to engage in casual sexual spaces like hookups and how their participation could be read as an expression of masculinity. Women are able to assert sexual autonomy and agency, to pursue the hookup space by "doing masculinity," because society is more comfortable with female masculinity than male femininity. Assuming this is true, what then undermines women's “masculine" sexual autonomy and prevents them from remaining as agentive subjects and equal pleasure-receivers in hookups?

It could be suggested that the inability to retain masculine agency is the threshold for entering into gender liminality. As female bodies enter the hookup space, they exit their historically austere feminine-object space into one of blithe masculine-subjectivity. What appears to compromise the completion of eluding the restrictive trappings of femininity is the female internalization of and attachment to accomplishing femininity, a significant part of which is the learned desire to be seen by the other as a wanted object — in this case, by their male hookup 


\section{Vivid 12}

pursuit. Lisa Wade suggests that women's desire to be wanted and sexually attractive to men overrides their desire for sexual agency and pleasure (England, 2016), with journalist Ariel Levy maintaining how women seem most concerned about whether men consider them "hot"

(Armstrong, Hamilton, et al., 2010). Essentially, as England's review asserts, women are enough "masculine" to maintain a casual energy, but not enough for their own pleasure (2016). While the hookup space prides itself as a source of free sexual expression, with women able to "do masculinity" intentionally and proactively by exploring their sexuality outside of committed relationships, it appears as though they are not performing masculinity to completion. On the contrary, one could propose that only if women were to receive as much pleasure as men would there be a complete performance of masculinity. This incompleteness is cause for their liminal status between the gender binary.

\section{Hookups vs. Relationships}

If casual hookups constrain female sexual subjectivity and promote pleasure inequities, why aren't more women pursuing committed relationships? Wouldn't a negation of subjectivity in the hookup space be grounds for the pursuit of a space where it is more likely they will receive lasting equal rights, e.g. committed relationships? Research evidences how long-term monogamous relationships are not the preferred alternative to hookups (Armstrong, Hamilton, et al., 2010), and how the informal aspects of hookups may be construed as a defense against the vulnerability of committed relationships: The more someone hooks up with another person, the greater the likelihood that person will develop feelings for the other person, with students avoiding hooking up with the same person twice out of fear of "catching feelings" (England, 2016). Why might women be afraid of catching feelings? While women are less likely to be 
rejected in the hookup space, monogamous relationships require commitment and therefore place women in a more emotionally-vulnerable place (England, 2016). Women are not avoiding relationships because they fear emotional connection, but rather they fear the increased vulnerability and risk of rejection that accompanies spaces that involve emotional connection and commitment. Commitment is an important factor in a relationship because it manifests trust and security in the exclusivity and future of the relationship, as evidenced by Linda Waite and Kara Joyner's 2001 study that reports both sexes as more emotionally fulfilled when in sexually exclusive relationships that they believed would last a long time (Armstrong, England, and Fogarty, 2012). If women pursue hookups over relationships as a way of avoiding vulnerability, one might consider that these women consider mutual commitment, trust, and affection more high-risk than feeling unworthy through the objectification and degradation received from male peers.

Although some women report preferring the hookup space because it feels emotionally safer than relationships, relationships and hookups are not mutually exclusive pursuits. College students who partake in hookup culture mentioned "the talk" or DTR, the "define the relationship" talk, which officiates whether the relationship is exclusive (England, 2013). Attitudinal data suggest women are more interested in relationships than men, with nearly half of women reporting interest in a relationship with a recent hookup in contrast to thirty-six percent of men; yet, it is not clear whether one can attribute this to reporting bias, as female respondents may report information that ascribes to normative gender expectations (England et al., 2008). Evidently, even within a research study are social pressures to satisfy expectations of gender unavoidable. It is also suggested that women feel pressured to shape their emotional demeanor in a way that caters to the stereotypical male agenda of prioritizing casual sex over relationships, as 
evidenced by women's reluctance in expressing desire for a relationship out of fear of being seen as the type of girl who boxes the guy into a relationship (England et al., 2008). In other words, women not only deny themselves sexual reciprocity, but they also suppress their emotional desires as a defense against being viewed in a negative light by potential male partners. Another reason why women prefer not to express interest in a relationship may be a result of the preserved norms that institute men as initiators of physical and emotional connections. England et al. found that it is more than twice as likely for the hookup to take place in the male's room vs the female's, suggests how both sexes ascribe to double standards that deem the man as instigator and woman as receiver (2008). In fact, ninety percent of males and females agree that women should be able to ask men out on dates, yet males still initiate dates eighty-seven percent of the time (England et al., 2008). That males are the headmasters of the where, when, and how of hookup and dating practices preserves the double standard by encouraging males to become the authority and arbiter of which females receive approval and which receive rejection.

What can be derived from these females' attitudes about relationship-vulnerability is an interesting irony. In attempting to eschew vulnerability around rejection, one might consider how women still enter into an emotionally-vulnerable space in the hookup — one that presents itself as a formative alternative for fun and connection, but actually just trades rejection for unworthiness. While hookups are presented as a liberal gateway for women to coalesce sexual license with intentionality, engaging in sexual behaviors "the wrong way" or "too soon" lead women to self-stigmatize as damaged goods and be left feeling undeserving of relationships (England et al., 2008). Women also report a degree of self-conscious "gate-keeping" to prevent the hookup from going too far in lieu of self-actualizing their physical desires, as supported by Deborah Tolman's study of desire in adolescent girls (Armstrong, Hamilton, et al., 2010). What 


\section{Vivid 15}

this suggests is that while hookups appear to hold physical primacy, they also have the potential to compromise the sexual and emotional drives of women, causing them to become overconcerned with fulfilling injunctions around the "how" and "when" in order to have a chance at being viewed as "relationship-material" (England et al., 2008). Although women have a chance at being viewed as relationship-material if they abstain from sex on the first or second hookup, more than half of females report believing that the males they hook-up with will still think less of them afterward. This belief is not invalid, as one third of males report thinking less of females after the hookup (England et al., 2008). The proposed irony of women preferring hookups over relationships may be viewed as a contradictory stopgap, and not only because hookups unduly compromise women in sundry sexual and emotional dimensions. Women also appear to be rather concerned about whether they are viewed as relationship-material, which suggests that they may be using hookups as a gateway to relationships.

Aside from the vulnerability-avoidance aspect, Armstrong, Hamilton, et al. (2010) assert alternative reasons as to why some females opt out of relationships. A trend among young adults, particularly young white adults whose families are wealthy, is to focus on self-development and investments in career, school, and friendships over adult commitments, essentially putting off any adulting — a newly popularized gerund on social media that frivolously refers to conditions and behaviors of adulthood. Armstrong, Hamilton, et al. refer to students' hookup pursuits as a means for "limited liability hedonism", with oral sex safer than risking STDs or pregnancies, and friendships safer than romance or intense relationships (2010). Other aspects of relationships that women report as negative are the time commitment and lack of personal freedom. Women remark on how their insular relationships prevented them from meeting other people and 
competed with schoolwork and chosen majors, with one women mentioning, "I wouldn't mind having a boyfriend again, but it's a lot of work" (Armstrong et al., 2010, p. 26).

In addition to the vulnerability-risk and incompatible academic aims, additional reasons for preferring hookups over relationships manifest in how women speak of their experiences of inequality and abuse in past relationships. Women mention difficulties in coping with partners who are controlling and/or jealous, with reports of women having to flee the state when their safety was compromised and call the police when their ex-boyfriend was stalking them. Ten out of forty-six female correspondents interviewed by Hamilton and England experienced men using abuse to coerce them into staying in the relationship (Armstrong, Hamilton, et al., 2010). Although there tends to be more pleasure equity in relationships than hookups, these accounts reveal the presence of gender inequalities in relationships that may prompt some women to pursue hookups. Gender liminality is suggested here, too, as gender inequalities within relationships negate female agency and subjectivity until the female body is able to regain masculine-subject status by decisively asserting discontent and leaving the relationship.

\section{Conclusion: "What Does Gender Want?"}

This essay proposes that heteronormative female college students are placed in a state of gender liminality, a middle ground between masculine and feminine gender performances, in contexts where gender inequalities are present. Gender inequities, although higher in hookup spaces, are still present in committed relationships, as demonstrated by some women's reported partiality to hookups from having experienced discriminatory inequalities in relationships. The postmodern struggle for heteronormative female-bodied persons lies in how one is able to do femininity without losing their subjectivity in relational contexts. Is that the same thing as 
undoing femininity? What would undoing gender actually look like? Undoing gender suggests undoing the binary because the binary is the progenitor of inequality. Judith Butler (2004) distinguishes gender as in possession of its own desires, which are separate from an individual's desires, as individual desire and agency are subordinate to gender's agenda because of gender's institutional status. The proposed concept of gender liminality suggests what occurs when women try to break the boundaries of their gender (femininity) by dialectically using gender (masculinity). Using gender to undo gender ironically reinforces the binary that creates inequalities to begin with, and forces women into a liminal status of having to work very hard to maintain agency.

There appears to be an inherent doing essential in this undoing, as seen when a woman negates their feminine-object status by choosing to enter the hookup space as an autonomous masculine-subject, hastily transitioning back into feminine-object during the hookup, and then presenting as disinterested subject after the hookup. While college hookup spaces may be alluring to women who seek sexual freedom and equity outside of committed relationships, what hookup spaces do seem to offer is the chance for women to do something differently in regards to sexual expressivity, gender performance, and relational practices with male peers. Yet, as with most important social issues, changes in how people think about and perform gender must happen on an institutional level, or, at the very least, among persons of both genders, for it to mean something on an individual level. As Butler states, "Although being a certain gender does not imply that one will desire a certain way, there is nevertheless a desire that is constitutive of gender and, as a result, no quick or easy way to separate the life of gender from the life of desire. What does gender want?" (2004, p. 1-2). This essay has argued that gender wants liminality, at least for as long as it desires the binary. 


\section{Directions for Future Research}

A potential direction for future research includes examining how gender liminality intersects with the experience of heteronormative cisgender males. When does heterosexual masculinity compromise performance and access? Another direction is to research heterosexual cisgender females who report expressing their sexual needs and receiving sexual reciprocity in first hookups to elucidate what impacts their self-declaration and sexual agency. While it is understandable why the orgasm would be a reliable indicator of sexual pleasure, it is a malecentric indicator and is complicated by how orgasms have also been reported in situations that do not suggest true pleasure, as evidenced by cases of assault (Levin and van Berlo, 2004). An additional research direction could be to explore alternative indicators of sexual pleasure aside from the orgasm.

Other arenas this research compels are future studies of LGBTQ hookup spaces and nonmonogamous relationships. Do queer, non-binary, or nonconforming bodies report similar experiences of relationship-vulnerability and slut-shaming behaviors? Are norm-abiding internalizations as visible in queer hookup spaces as they are in heteronormative hookup spaces? How might femininity and masculinity be interrogated in non-binary spaces? Investigating expressions of desire and sexual subjectivity in spaces where heteronormative feminine and masculine presentations deconstruct may lend insights into the influence of non-binary persons on gender inequalities and power differentials, and whether the binary is necessary for desire at all. Is the presence of a binary essential for desire to function, or can desire exist outside of the binary? Can there still be difference without the binary? In regards to alternative coupling styles, studying non-monogamous relationships, such as polyamorous relationships, where consent and 
commitment are valued sans sexual exclusivity, might suggest that mutual affection and support can co-exist with casual sexual pursuits, and could therefore provide women who desire a confluence of warmth and informality with a viable alternative.

Allison, Rachel, Barbara J. Risman. 2013. “A double standard for 'Hooking Up': How far have we come toward gender equality?” Elsevier Social Science Research. 42:1191-1206. Armstrong, Elizabeth A., Laura Hamilton, and Paula England. 2010. "Is Hooking Up Bad for Young Women?” Contexts. 9(3):22-27.

Armstrong, Elizabeth A., Paula England, and Alison C. K. Fogarty. 2010. "Orgasm in College Hookups and Relationships.” Pp. 362-377 in Families as They Really Are, edited by Barbara Risman. New York: W. W. Norton.

Armstrong, Elizabeth A., Paula England, and Alison C. K. Fogarty 2012. "Accounting for Women's Orgasm and Sexual Enjoyment in College Hookups and Relationships.” American Sociological Review. 77(3):435-462.

Backstrom, Laura, Elizabeth A. Armstrong, and Jennifer Puentes. 2012. "Women's Negotiation of Cunnilingus in College Hookups and Relationships." Journal of Sex Research. 49(1):1-12. Butler, Judith. 2004. Undoing gender. New York, NY. Routledge.

England, Paula, Emily Fitzgibbons Shafer, and Alison C.K. Fogarty. 2008. "Hooking Up and Forming Romantic Relationships on Today's College Campuses.” Pp. 531-47 in The Gendered Society Reader, Third Edition, edited by Michael S. Kimmel and Amy Aronson. New York: Oxford University Press.

England, Paula. 2015. "Sometimes the Social Becomes Personal: Gender, Class, and Sexualities.” American Sociological Review. 81(1):4-28. 
England, Paula. 2016. Is a "Warm Hookup" an Oxymoron? Contexts. 15(4): 58-59.

Goffman, Erving. 1977. “The Arrangement between the Sexes.” Theory and Society. 4(3): 301-331.

Levin, Roy J., Willy van Berlo. 2004. "Sexual arousal and orgasm in subjects who experience forced or non-consensual sexual stimulation — a review." Journal of Clinical Forensic Medicine. 11(2):82-88.

Risman, Barbara J. 2004. "Gender as a Social Structure: Theory Wrestling with Social Change.” Gender \& Society. 18(4):429-50.

The Media Education Foundation. 2013. Understanding Hookup Culture with Paula England. (Video). https://www.youtube.com/watch?v=L3Q2L7YQ2Hk. (Accessed 7 Aug. 2017.)

West, Candace, Don H. Zimmerman. 1987. “Doing Gender.” Gender and Society. 1(2): 125-151. 